\title{
Mandatos y consejos en la filosofía práctica moderna*
}

\section{Commands and counsels in modern practical philosophy}

\author{
LUCA FONNESU \\ Università di Pavía (Italia)
}

RESUMEN. Este artículo trata de la distinción entre órdenes y consejos en la filosofía práctica moderna como doctrina de deberes. La distinción juega un papel esencial en el pensamiento cristiano de Thomasius por su diferenciación entre las distintas esferas de la vida práctica, iustum, honestum y decorum, por ejemplo, las esferas de la ley (iustum), ética correcta (honestum) e incoercible comportamiento externo - con significado ético-, incluyendo las buenas maneras (decorum). En la filosofía práctica de Kant, la distinción entre mandatos y consejos corresponde a la distinción entre moralidad y prudencia como búsqueda de la felicidad. La vida moral está regida por la ley moral y por la idea del deber, que organiza en su propia perspectiva los otros aspectos de la actividad práctica y los diferentes tipos de deberes. Según pasó el tiempo, Kant estaba cada vez más interesado en la realización histórica de la moralidad como Moralisierung a través de la promoción de sus condiciones externas como la coexistencia pacífica a través de la ley jurídica y el desarrollo de las relaciones intersubjetivas a través de $Z i$ vilisierung y buenas maneras. La doctrina de los deberes de Kant y del siglo dieciocho no deja espacio para una moralidad más allá del deber como supererogation, un concepto que ha recibido una nueva atención en el debate contemporáneo moral y puede seguir siendo discutido en una perspectiva kantiana.
AbSTRACT. This paper addresses the traditional distinction between commands and advices in modern practical philosophy as doctrine of duties. The distinction plays an essential role in Christian Thomasius' thought for his differentiation between distinct spheres of practical life, iustum, honestum and decorum, i. e. the spheres of law (iustum), proper ethics (honestum) and incoercible external behaviour - with ethical meaning -, including good manners (decorum). In Kant's practical philosophy, the distinction between commands and counsels corresponds to the distinction between morality and prudence as pursuit of happiness. Moral life is ruled by moral law and by the idea of duty, that organizes in its own perspective the other aspects of practical activity and the different kinds of duties. As time passed, Kant is more and more interested to the historical realization of morality as Moralisierung through promotion of its external conditions such as pacific coexistence through the juridical law and improvement of intersubjective relations through Zivilisierung and good manners. Kant's and eighteenth century's doctrine of duties leave no space for a morality beyond duty as supererogation, a concept that has received a new attention in contemporary moral debate and can still be discussed in a Kantian perspective.

* Traducción de Sandra Viviana Palermo. Este trabajo forma parte del proyecto de investigación HUM2007-61018 del Ministerio de Educación y Ciencia. 
Palabras clave: Ética, deber, Kant, moral y Keywords: Ethic, duty, Kant, moral and law. derecho.

\section{Introducción}

El binomio conceptual mandatos/consejos tiene raíces muy lejanas que se remontan a la reflexión sobre los officia, a partir de los cuales, y de la oportunidad de su diferenciación, comienzan su propio recorrido histórico. A la sistematización de Tomás de Aquino - todavía presente en el De legibus de Suárez- sigue, dicho en pocas palabras, la polémica luterana ${ }^{1}$.

En la filosofía práctica moderna este binomio conceptual ha sido reelaborado y transfigurado heredando las dificultades de la distinción entre esfera interna y esfera externa, entre amor y justicia, entre Evangelio y Ley Mosaica, que había caracterizado su nacimiento y su desarrollo ${ }^{2}$. Desde luego, la perspectiva no es más la de la perfección, de sus eventuales grados y del camino hacia la salvación, sino que se trata de la perspectiva mundana de un camino ético individual y de la regulación de la relación intersubjetiva en sus diferentes formas. Éste es el elemento esencial de la moderna doctrina officiorum, cuyo punto de partida es el derecho natural moderno y que alcanza su punto más alto, y a su vez un nuevo punto de partida, con Kant. La historia sucesiva conduce a la reflexión ética contemporánea.

La reformulación del binomio mandatos/consejos sigue fundamentalmente dos trayectorias que llegan, de distintas maneras y con diversas vicisitudes, hasta nosotros. En primer lugar, es sobre la base del binomio mandato/consejo que madura la distinción entre derecho y ética, basada a su vez sobre la distinción entre esfera externa y esfera interna. Aún en 1961, uno de los mayores filósofos del derecho del siglo Xx, Herbert Hart, llamaba la atención sobre este fundamento de la distinción entre obligaciones morales y obligaciones jurídicas. Aun aceptando la necesidad de una reinterpretación y reformulación, según Hart, esta perspectiva contenía implícitamente elementos actuales de la distinción entre ética y derecho ${ }^{3}$.

En segundo lugar, otro aspecto que hay que tener en cuenta, es la idea de una gradación o de una jerarquía de las acciones moralmente significativas;

1 Sobre los problemas generados por el binomio mandatos/consejos en edad premoderna consultar S. Vecchio, Precetti e consigli nella teologia del XIII secolo, en "Consilium». Teorie e pratiche del consigliare nella cultura medievale, comp. C. Casagrande, C. Crisciani, S. Vecchio, Firenze, SISMEL-Ed. Del Galluzzo 2004, pp. 33-56.

2 Con la lucidez que lo caracteriza, Norberto Bobbio ha escrito uno de los pocos textos explícitamente dedicados a este tema en el pensamiento moderno, Comandi e consigli, en Raccolta di scritti in onore di Arturo Carlo Jemolo, Milano, Giuffré 1964, vol. IV, pp. 73-98.

3 Cfr. H. L. A. Hart, The Concept of Law (1961), Oxford, Clarendon Press, 1994 (cap. VIII, § 2). 
idea que recupera el contenido conceptual de la distinción cristiana entre mandato y consejo. También en este caso, con una historia de oscilaciones, que asistió a la decadencia y — durante el siglo XX - al resurgimiento de la noción de «deber», se trata de un problema que llega hasta el debate contemporáneo, perdiendo desde luego la referencia terminológica al binomio conceptual que nos interesa, pero manteniendo mucho más que las líneas fundamentales. Las páginas siguientes están dedicadas, ante todo, a este segundo aspecto.

Quien intentó explicitar el sentido de la teoría del derecho natural moderno como doctrina de deberes fue Pufendorf, el cual, en una carta a Thomasius, sostuvo la necesidad de dejar de tratar la teoría moral secundum virtut tes ${ }^{4}$ y de comenzar a tratarla secundum officia, y decide ponerle el título de De officio hominis et civis (1673) a la exitosa vulgarización de su obra principal, el De jure naturae et gentium, de 1672. Pero ya Hobbes había sido claro: en este libro - escribe Hobbes en el prólogo a la segunda edición del De cive - se describen «hominum officia, primo ut hominum, deinde ut civium, postremo ut Christianorum». Como demuestran las palabras con las cuales comienza el capítulo 25 del Leviatán (1651), el filósofo inglés muestra con mucha lucidez el carácter problemático de diferentes formas de prescripción y del lenguaje prescriptivo: «Cuán falaz es juzgar de la naturaleza de las cosas por el uso ordinario e inconstante de las palabras, aparece con más claridad que en ninguna otra cosa en la confusión de consejos y órdenes [mandatos], que resulta de la manera imperativa de hablar en ambos, y en muchas otras ocasiones. En efecto, las palabras: Haz esto, son los términos en que se expresa no sólo el que manda, sino también el que da consejo, y el que exhorta. Sin embargo, pocos dejarán de advertir que éstas son cosas diferentes, o tendrán dificultades para distinguir cuándo se trata de determinar quién habla y a quién va dirigida la palabra, y en qué ocasión» (trad. es. de M. Sánchez Sarto, México DF, Fondo de Cultura Económica, p. 209).

\section{Thomasius}

Ampliamente influenciado por Hobbes, Christian Thomasius construye su propia filosofía práctica sobre la base de la articulación entre mandato, imperium, y consejo, consilium. La obra más importante de Thomasius, Fundamenta juris naturae et gentium (1705) ${ }^{5}$, ofrece la mayor exposición moderna del binomio conceptual mandato/consejo y constituye el aporte más importante, anterior a Kant, con vistas de una diferenciación de las prescripciones y

${ }^{4}$ Samuel Pufendorf, Briefwechsel, hrsg. von D. Döring, Berlin, Akademie 1996, p. 197.

5 Aquí utilizo la reimpresión anastática de la cuarta edición (1718): Aalen, Scientia Verlag 1979 y a lo largo del texto, libro, capítulo y párrafo correspondientes. 
de los ámbitos normativos que éstas generan. Precisamente con Thomasius la distinción entre ética y derecho se introduce con claridad en la filosofía práctica moderna.

Thomasius discute incesantemente con la tradición, es decir con sus propias fuentes (cfr. Fundamenta, Pref., § XII), entre otras cosas porque, para el filósofo, este diálogo polémico constituye una ocasión para una discusión crítica de sus obras anteriores. Thomasius es conciente de que la articulación entre los distintos tipos de normas y entre los diferentes ámbitos normativos es el elemento más específico de su propia reflexión; de hecho, más de una vez se detiene a subrayar que los «doctores scolastici» han confundido derecho y ética (es decir, en su lenguaje, la esfera del justum con la esfera del honestum), y que el mismo error ha sido cometido por un pensador de la categoría de Pufendorf: por otra parte, éste no ha tenido en cuenta un ámbito normativo, el del decorum, cuyas raíces se remontan, como en el caso del ámbito del officium, a Cicerón, y que constituye un elemento importante en la arquitectura conceptual de Thomasius. Es necesario decir algo sobre el decorum, porque volveremos sobre este tema.

Esta noción, que habría de tener gran importancia en la tradición sucesiva, nace con Cicerón: se trata de la armonía en los comportamientos exteriores que refleja la armonía interior, una suerte de traducción estética de la actitud ética, es decir, un elemento estético que adquiere relevancia ética y que, a la vez, es fuente de officia ${ }^{6}$. He aquí el origen - si bien remoto- de una reglamentación normativa de la conducta que constituirá lo que Elías ha llamado «civilización de las buenas maneras», una parte integrante del proceso de civilización ${ }^{7}$. Thomasius conoce bien los estudios renacentistas cuyo referente es Cicerón y también la teoría moral sucesiva; éstos han desempeñado un rol aun después de Thomasius, incidiendo incluso, directa o indirectamente, en el pensamiento contemporáneo. Con respecto al decorum, en la presentación de los Fundamenta, Thomasius recuerda explícitamente la importancia de un seguidor holandés de Hobbes, Lambert Velthuysen, autor en 1651 de una Dissertatio de principiis justi et decori. El filósofo se detiene varias veces sobre esta cuestión, mencionando numerosos autores, como Aristóteles, Cicerón, Baltasar Gracián, o autores italianos, como Stefano Guazzo y Giovanni della Casa ${ }^{8}$.

6 Véase Cicerone, De officiis, I, 93 y suc.

7 N. Elias, El proceso de civilización. Investigaciones sociogenéticas y psicogenéticas, trad. de R. García Cotarelo, México DF-Madrid-Buenos Aires, Fondo de Cultura Económica, 1989.

8 Con respecto a Alemania v. E. Bonfatti, La «civil conversazione» in Germania. Letteratura del comportamento da Stefano Guazzo a Adolf Knigge, Udine, Del Bianco, 1979, y la vasta investigación de N. Pirillo, cuyo eje central es Kant, pero que puede resultar útil, dadas las numerosas indicaciones que contiene, L'uomo di mondo tra morale e ceto. Kant e le trasformazioni del Moderno, Bologna, Il Mulino, 1987. Con respecto al Galateo di Della Casa, véase también C. Scarpati, Con Giovanni Della Casa dal «De officiis» al «Galateo», en Id., Studi sul Cinque- 
Las consideraciones críticas de Thomasius muestran entonces de manera eficaz que el filósofo es conciente de las novedades más importantes y de los elementos peculiares del pensamiento que ha elaborado en su madurez. Sobre la base de una antropología cuyos contornos han sido delineados en los primeros capítulos del primer libro ${ }^{9}$, Thomasius sostiene que la voluntad constituye el primer objeto de la filosofía moral (o derecho natural en sentido lato, la filosofía práctica en su conjunto, que abarca todos los ámbitos) y que su relación con el temor y la esperanza (metus et spes) es el mecanismo fundamental de la acción y de los procesos normativos que pretendan reglamentarla.

Los Fundamenta son también el resultado de una crisis «pesimista» del pensamiento de Thomasius (lo ha mostrado Werner Schneider en un importante libro de $1971^{10}$ ): tal pesimismo se nota, entre otras cosas, en el juicio negativo del autor sobre la necesidad de la existencia de normas que regulen las acciones humanas. Tal necesidad, al contrario de lo que comúnmente se piensa, no es el signo de la excelencia humana respecto de las otras criaturas, sino más bien de su miseria (Fundamenta, I. IV, § II). El hecho es que las normas pueden tener dos formas distintas, con caracteres diferentes y con ámbitos normativos distintos: se trata precisamente del consilium y del imperium (Fundamenta, I. IV, $\S \S$ XXXII-XXXIII), y sobre esta distinción Thomasius funda su propia filosofía práctica.

Mandato y consejo son para Thomasius normae vivendi que prescriben las acciones (futuras); ambos tienen en común la posibilidad de generar la obligación, obligatio, si bien de naturaleza distinta. Ambas prescripciones tienen el objetivo de suscitar esperanza y temor (Fundamenta, I. IV, $\S$ XXXV); la diferencia está en el tipo de daños y de resultados que pronostican. El consejo es una norma que da a conocer el daño producido por las pasiones incontroladas y la esperanza del bien verdadero, mientras que el mandato plantea daños y ventajas no naturales, arbitrarios, es decir ab hominibus inventa (Fundamenta, I. IV, $\S \S$ LIII-LIV). A ello se debe que contravenir el consejo trae consigo una serie de daños que tienen su raíz en la naturaleza de las cosas, en última instancia, su causa es la naturaleza pasional del hombre incontrolado que no logra entender cuál es su bien verdadero: en suma, es la misma naturaleza (en definitiva: Dios) la que castiga al hombre incapaz de controlar sus propias pasiones. Muy diferente es el daño que castiga a quien transgrede el mandato, pues en este

cento italiano, Milano, Vita e Pensiero, 1982, pp. 126-155. Sobre el papel de Thomasius en la historia del término «decorum», véase M. Beetz, Ein neuentdeckter Lehrer der Conduite. Thomasius in der Geschichte der Gesellschaftsethik, en W. Schneiders (hrsg.), Christian Thomasius (1655-1728). Interpretationen zu Werk und Wirkung, Hamburg, Meiner, 1989, pp. 199-222.

9 En el primer libro de la obra Thomasius presenta el cuadro teórico, mientras que en los libros siguientes, el segundo y el tercero, desarrolla la aplicación de los principios, representada por una doctrina officiorum.

10 W. Schneiders, Naturrecht und Liebesethik. Zur Geschichte der praktischen Philosophie im Hinblick auf Christian Thomasius, Hildesheim - New York, Olms, 1971, específicamente, pp. 230 sig. 
caso se trata de un daño arbitrario; un daño que proviene de los otros hombres, de aquellos que tienen legitimidad para prescribir el mandato. Evidentemente, aquí se puede percibir, in nuce, la distinción entre ética en sentido estricto y derecho, correspondiente a la diferenciación entre esfera interna y esfera externa: la sanción natural del consejo está en la incapacidad de aferrar el bien verdadero del control de las pasiones, con los daños que esta incapacidad produce; la sanción humana del mandato, en cambio, consiste en el castigo de parte de los otros hombres. Tanto así es que para Thomasius la sanción natural alcanza al sabio, sapiens, mientras que para los insipientes — que sin duda son la mayoría- es necesaria la sanción humana.

La obligación (obligatio) es una inclinación o tendencia (inclinatio) de la voluntad debida a un temor o a una esperanza (Fundamenta, I. IV, § LX), y puede ser externa o interior, correspondiendo de esta forma al binomio comando/consejo: la obligación interior nace de la conciencia del peligro natural que deriva de Dios, mientras que la obligación externa nace de la esperanza o del temor de un premio o de un peligro de parte del arbitrio humano (Fundamenta, I. IV, § LXI).

Aquí hace su aparición ese binomio interno/externo, que habría de ser tan importante para la distinción entre ética y derecho y que remite no tanto a la obligación en sí misma, sino al tipo de coacción que se ejerce sobre la voluntad, es decir al tipo de sanción que se plantea: interna o externa, natural o humana. Los stulti tienden a no tener en cuenta la obligación interior del consilium, o porque ignoran el orden necesario de las cosas o porque lo desprecian y no lo temen, mientras temen magis mala arbitraria que son el resultado de la transgresión del mandato de origen humano, que trae consigo una pena humana (Fundamenta, I. IV, § LXIII). El necio teme más que nada las penas externas, arbitrarias, humanas, y obra en vista del premio externo; el sabio teme ante todo la pena interior y obra por la virtud que es premio de sí misma (cfr. Fundamenta, I. IV, §§ LXIX, LXVII). La conducta del sabio y la del necio se basan entonces sobre dos principios distintos: el sabio se basa simplemente en el consejo, porque es conciente de la necesidad de controlar las propias pasiones y no necesita el sostén de ninguna otra imposición humana; el necio, en cambio, es controlable sólo en virtud de un sostén externo, es decir del mandato: stulti magis imperio, sapientes, i. e. etiam ii, qui sapere incipiunt, magis consilio reguntur (Fundamenta, I. IV, § LXV).

De este modo, en Thomasius, la distinción entre consejo y mandato introduce ámbitos normativos distintos, todos tendentes a la conquista de la felicidad, o bien, en la interpretación de Thomasius, de la paz, o de la quietud interior y exterior. Es cierto que ahora es la felicidad, y ya no la socialitas ${ }^{11}$, el

11 W. Kersting, Das starke Gesetz der Schuldigkeit und das schwächere der Gütigkeit, en Id., Recht, Gerechtigkeit und demokratische Tugend. Abhandlungen zur praktischen Philosophie der Gegenwart, Frankfurt a. M., Suhrkamp, 1997, pp. 74-120, pp. 84-85. 
fundamento de la articulación normativa, y por ende el valor al que se hace referencia; pero esto es así porque la socialitas ha sido absorbida dentro de la meta representada por la conquista de la felicidad: es una condición para alcanzar dicha meta, como paz externa. De un enfoque de este tipo nace la distinción entre honestum, decorum y justum; los dos primeros ámbitos se basan en el consejo, el último, el del justum, en el mandato.

El binomio mandato/consejo no constituye la base de una simple bipartición de ámbito, sino de una tripartición: de hecho, la paz externa no se funda sólo en las acciones exteriormente correctas, justas, sino también en la promoción extrajurídica de las relaciones intersubjetivas a través del decorum, que es fruto del consilium y que constituye una obligación interior. La diferenciación de las normas, y de los distintos ámbitos normativos correspondientes a tales normas, responde a un proyecto pedagógico o, si se quiere, a una articulación de las diferentes formas de prescripción que puedan garantizar las distintas formas de paz, y por ello, de felicidad, y a la vez promover la felicidad, a través de la paz subjetiva e intersubjetiva, aun para los stulti, o por lo menos para todos aquellos que no carezcan completamente de indoles virtutis. La función de las normas tiene que ver, de hecho, con la obtención de la paz interior, mediante la moderación de los apetitos (esfera de lo honestum), de la paz externa, mediante acciones pacíficas (esfera del decorum), y de la paz, aun externa, mediante el impedimento de las acciones externas que la puedan turbar (Fundamenta, I. IV, § LXXIII). Esto nos permite notar que la función de las normas de lo honesto - consilia - aunque aparentemente positiva, se limita a la moderación de los afectos y de las pasiones, la función de las normas del decoro - también consilia - es totalmente positiva, mientras que la función de las normas de lo justo, los imperia, es exclusivamente negativa: se trata, en este caso, de prohibir los extrema mala (Fundamenta, I. V, § XLVIII). Y las reglas son las siguientes: para lo honesto: Quod vis, ut alii sibi faciant, tute tibi facies; para el decoro: Quod vis ut alii tibi faciant, tu ipsis facias; para lo justo: Quod tibi non vis fieri, alteri ne feceris (Fundamenta, I.V, $\S \S \mathrm{XL}, \mathrm{XLI}, \mathrm{XLII})$.

La obligatio interior caracteriza ya sea el ámbito de lo honestum, ya sea el del decorum. Mas las reglas de lo honesto tienen que ver con las acciones interiores (ad moderandos affectus suos, cfr. Fundamenta, I. V, § XVIII), mientras que las reglas del decoro tienen que ver con las acciones externas, es decir, con aquellas que promueven la paz externa para obtener la benevolencia de los demás (y son por naturaleza intersubjetivas).

Sólo las reglas de lo justum son completamente externas, y a una obligación externa - en el sentido en que hemos visto - corresponde un ámbito externo de aplicación, así como también una obligación para con los demás a la que se puede estar sujeto, y que responde a la necesidad del mantenimiento de la paz externa (obviamente, ésta también es intersubjetiva) (véase Fundamenta, I. IV, § XC). La coerción puede ejercerse entonces sólo en el ámbito 
de lo jus, de lo justum, y viceversa, el ámbito de la coerción, de la coacción, puede ser únicamente el ámbito del derecho: el ámbito interno queda ajeno a la coacción, y tampoco la obligación interna del decorum, que tiene que ver con las relaciones intersubjetivas, puede estar sujeta a una coacción (ad decorum nemo cogi potest, Fundamenta, I. V, § XXI). La virtus, la cualidad moral individual abraza el ámbito de lo honestum y del decorum, mientras que la justitia constituye el fundamento de lo justum (Fundamenta, I. V, § XXV).

La articulación normativa con sus respectivos ámbitos queda confirmada en la distinción entre los distintos ámbitos de la filosofía práctica (el derecho natural o filosofía moral en sentido lato), que se dividen en ética (ámbito de lo honestum), política (ámbito del decorum) y derecho en sentido estricto (ámbito de lo justum) (Fundamenta, I. V. § LVIII). Es importante aclarar que, en Thomasius, el término política, como ámbito del decorum, no tiene un significado afín al moderno, y tampoco a la Staatsklugheit; por el contrario, el ámbito de esta última de alguna manera se contrapone al del decorum.

No es difícil notar que el espacio específico de la ética, es decir de lo honesto, parece ser un espacio muy reducido, que consiste en el control de las propias pasiones, aunque para Thomasius esto implique una actitud positiva también respecto de las otras esferas: el sabio, o al menos aquel que intenta alcanzar la sabiduría (no existe un sabio in summo grado, Fundamenta, I. VII, § XXXII, es decir que se trata de una rara avis in terra, $\S$ LXXVI), también respeta las reglas del decoro y de lo honesto. La sabiduría incluye la virtud en sus distintos aspectos, también en lo que hace al comportamiento externo y, a fortiori, a la justicia (Fundamenta, I. VI, § LXXV). Las tres esferas normativas deben ser coordinadas entre sí y se disponen en una suerte de escala jerárquica con diferentes grados de accesibilidad -o urgencia: los consilia de lo honesto son menos urgentes; los imperia de lo justo, en cambio, son intensamente urgentes, pues la violación de los mismos produce un estado de conflicto. Violar las reglas de lo honesto no es nocivo para los otros hombres y violar las reglas del decoro no produce en sí mismo odio y conflicto, si bien es causa de cessantis amoris, quae cessatio parum quidem differt ab initio odii. La violación de las reglas de lo justo, en cambio, es causa de conflictos y de odii extremi... ex natura communi humani generis (Fundamenta, I. VI, $\S$ LXXII). Las reglas de lo justo, dado que son las más urgentes, también son las más accesibles, y constituyen el punto de partida para conducir a los hombres a la felicidad verdadera, según el proyecto pedagógico del que hemos hablado: más accesibles las reglas de lo justo, menos las del decoro, y aún menos las de lo honesto. Para Thomasius ésta es la unica et optima methodi regula..., a facilioribus pergendum ad difficiliora (Fundamenta, I. VI, $\S$ LXXVIII).

Los consilia cubren toda la esfera de lo que no puede ser exigido por coacción en tanto se basa en una obligación interior. Este ámbito está compuesto, según Thomasius, por la esfera de lo honestum y del decorum: a esta 
última esfera le es asignado un vasto espacio, cargado de significado ético ${ }^{12}$. Entre los dos polos, autocontrol ideal del sabio en lo honestum y reglamentación sólo jurídica y externa de lo justum, el decorum se constituye como el vasto ámbito de la acciones externas sin una determinación definida pero éticamente significativo, ya que remite al espacio de las relaciones intersubjetivas.

La acepción thomasiana de «política» — no demasiado clara - a la cual debería corresponder el decorum, remite al comportamiento privado, individual, de la ética social, inclusive del buen comportamiento y de las buenas maneras, siguiendo las huellas del decorum ciceroniano y de sus numerosas reinterpretaciones. Por otro lado, es éste mismo el significado de la política como prudencia, Klugheit, que Thomasius expone en el Kurzer Entwurff der politischen Klugheit, escrito poco después que los Fundamenta (1707).

El interés de Thomasius por la ética social y por la conduite no sorprende: el ciclo de clases previsto para el año 1687 en la Universidad de Leipzig, que generó sorpresa y escándalo, el Discurs, welcher Gestalt man denen Frantzosen im gemeinen Leben und Wandel nachahmen sollte, tenía como punto de referencia principal la exitosa versión francesa del Oráculo manual y arte de la prudencia (1647) del jesuita Balthasar Gracián, L'homme de cour de Amelot de la Houssaye, de $1684^{13}$. Sin embargo, se sabe, el escándalo consistía en programar clases en alemán y no en latín. En realidad, la relación de Thomasius con Francia y con la conduite responde a un objetivo polémico que va más allá del texto de Gracián: se trata de modernizar la vida cultural alemana y la filosofía poniendo la mirada fuera de Alemania, y efectivamente el texto de 1707, el Kurzer Entwurff, está dedicado al comportamiento, pero se trata del comportamiento considerado como fruto de una sana razón utilizada por el hombre práctico, por el burgués ${ }^{14}$.

En los Fundamenta el rol del decorum es mucho más amplio que en el breve tratado de 1707: allí el decorum constituye un ámbito normativo que remite a una esfera externa de acciones buenas y de renuncia, también en nombre de una magnanimidad para con el prójimo que no se reduce simplemente a las buenas maneras, si bien las incluye. Se trata de algo que va más allá del deber jurídico en la relación intersubjetiva, y que Thomasius llama, como ya habían hecho otros antes que él (Pufendorf, por ejemplo) officia humanitatis. El binomio amor/justicia y el contenido conceptual de la antigua distinción entre con-

12 Para Thomasius el decorum «no es sólo una pátina superficial, sino que se trata de una condición esencial de la sociedad humana, sin la cual la vida social tendría necesidad de ser gobernada o por el amor absoluto o por el temor absoluto» (F. M. Barnard, Rightful decorum and rational Accountability. A forgotten Theory of civil Life, en W. Schneiders (hrsg.), Christian Thomasius, cit., pp. 187-198, p. 187)

13 V. la edición París, Editions Ivrea, 1993. Con respecto a Gracián es menester indicar el nuevo y útil léxico realizado por E. Cantarino y E. Blanco, Diccionario de conceptos de Baltasar Gracián, Madrid, Cátedra 2005.

14 Sobre el Kurzer Entwurff véase E. Bonfatti, op. cit., pp. 171 y sig. 
sejos y mandatos como formas distintas del valor y de la prescriptividad reaparece en la tradición del derecho natural: algunos deberes son esenciales para la subsistencia, para el esse de la sociedad - officia hominis comunissima, había escrito Pufendorf - otros contribuyen a su bene esse. La terminología con la cual se designan estos distintos tipos de deberes corresponde - pero con un significado inverso - a la distinción ambrosiana: de hecho, por lo menos hasta Kant se habla de deberes perfectos y de deberes imperfectos ${ }^{15}$. Los deberes perfectos son los deberes esenciales, y por ende susceptibles de coerción, mientras que los deberes imperfectos son deberes éticamente significativos pero que no constituyen una condición esencial para la convivencia pacífica, y por lo tanto no son susceptibles de coerción. Los deberes perfectos son entonces, en el contexto moderno, los deberes accesibles e ineludibles, aquellos que, en el lenguaje de Thomasius, deben ser impuestos a los stulti (para el justo, ya lo había dicho Lutero, la ley externa no es necesaria, y es lo mismo para el sabio de Thomasius); los deberes imperfectos tienen su espacio específico más allá de los perfectos y contribuyen a mejorar el bienestar de los individuos y de la sociedad. La inversión, con respecto a la tradición cristiana, tiene su raíz en un contexto axiológico distinto: el valor no está puesto en el grado de perfección y en el horizonte de la salvación, sino en la conquista de la felicidad y de los medios indispensables para alcanzarla, sobre la base, obviamente, de la convivencia pacífica; un valor que puede quedar garantizado sólo gracias a la coacción.

\section{Kant}

En Kant la diferenciación y la articulación de las prescripciones y de sus respectivos ámbitos normativos constituye un tema de notable complejidad que incluye a la mayor parte de los temas aquí tratados y va aún más allá de ellos; sin embargo, a pesar de la riqueza y de la calidad de la literatura kantiana, se trata de un tema explorado sólo parcialmente. La investigación más reciente ha puesto en evidencia que existen todavía muchos aspectos de la reflexión kantiana sobre la ética que requieren un análisis más profundo y que pueden constituir elementos de notable importancia no sólo en lo que respecta a la interpretación del pensamiento de Kant sino también en lo concerniente a utilización teórica de la herencia kantiana. Digo esto porque el modo de leer la reflexión kantiana sobre la ética se ha modificado notablemente en los últimos decenios: pensemos en el interés que ha despertado la antropología y sus relaciones con las reflexiones éticas y con la filosofía de la historia (un ejemplo de esto es, sin duda, Norbert Hinske ${ }^{16}$ y su escuela), o en el reciente interés

15 Sobre este punto v. W. Kersting, art. cit.

16 Un nuevo interés por la antropología de Kant surge a partir de un artículo de Hinske: Kants Idee der Anthropologie, in H. Rombach (hrsg.), Die Frage nach dem Menschen. Aufriss 
por la Metafisica de las costumbres, por fin vista como una parte integrante del recorrido ético kantiano y no como una obra menor.

El análisis kantiano de la esfera práctica se funda en la idea de que el obrar humano, siempre y cuando no se trate de una acción realizada sin reflexionar y por hábito, es un obrar que resulta de principios racionales (Ak. IV, 412; pp. 90-91) ${ }^{17}$. En este contexto volvemos a encontrar la distinción entre mandatos y consejos: toda la esfera de la moralidad (que incluye o incluirá al derecho) está bajo la categoría del mandato incondicionado (la ley moral, que para los hombres, seres racionales finitos, es un mandato), si bien Kant también presenta otras formas de prescripción, condicionadas, que prescriben una acción no como buena en sí misma sino como buena en virtud de otra cosa. Se trata en este caso de las reglas de la habilidad, y, sobre todo, de los consejos en vista de un fin que todos tienen, la felicidad: consejos de la prudencia ${ }^{18}$. Y al menos una vez, en la Fundamentación de la metafísica de las costumbres, Kant acerca el binomio mandatos de la moralidad/consejos de la prudencia a la terminología latina: se trata de preacepta y de consilia (Ak. IV, 418; p. 100). La formulación de la distinción de los distintos principios - mandato por un lado y reglas y consejos por el otro- como distinción entre imperativos categóricos e hipotéticos será abandonada por Kant a partir de la segunda Crítica, y el término imperativo será utilizado sólo para el imperativo categórico ${ }^{19}$. Sin embargo, esto no habrá de implicar la cancelación de las respectivas esferas normativas, sino una articulación diferente de las mismas.

Entre los principios condicionados del obrar, Kant siempre atribuirá un rol y una posición de privilegio a la esfera de los consejos de la prudencia. Por otra parte, los consejos de la prudencia no consisten solamente en la identificación de los medios, sino también en la identificación de nuestros fines en virtud de nuestros deseos sensibles, pues la felicidad de cada uno, cuando no se trate de una simple denominación o, como escribe Kant, de un simple «título», no es algo que puede determinarse a priori (y también por este motivo no puede constituir un principio de la moralidad, objetivo y necesario),

einer philosophischen Anthropologie. Festschrift für Max Müller zum 60. Geburtstag, Freiburg/München, Alber, 1966, pp. 410-427.

17 Para las obras de Kant - cuyas indicaciones coloco a lo largo del texto - utilizo la edición de la Academia, con la abreviación Ak., a la cual siguen el número del volumen y el número de las páginas; separado de éstos con un punto y coma sigue el número de las páginas de la traducción española utilizada. Las traducciones españolas utilizadas son: La metafísica de las costumbres (edición española de Adela Cortina), Madrid, Tecnos, 1989; Crítica de la razón práctica (edición española de Roberto R. Aramayo), Madrid, Alianza Editorial, 2002; Fundamentación de la metafísica de las costumbres, (edición española de Roberto R. Aramayo), Madrid, Alianza Editorial, 2002.

18 Sobre la compleja cuestión de la felicidad en Kant, cfr. D. Tafani, Virtù e felicità in Kant, Firenze, Olschki, 2006; así como Roberto R. Aramayo,

${ }_{19}$ Lo nota S. Bacin, Massime e principi pratici in Kant, en "Annali dell'Istituto Italiano per gli studi storici», XVI, 1999, pp. 323-362, p. 331. 
sino que debe ser buscada. Los consejos de la prudencia consisten entonces en la identificación de los fines que componen nuestro proyecto de felicidad, como así también en la identificación de los medios que conducen a la realización de dichos fines. El mantenimiento de la prudencia como ámbito normativo específico es significativo y constituye un tema de gran importancia, que desempeñará un rol sistemático también respecto de la antropología ${ }^{20} ;$ y se podría añadir que durante mucho tiempo - lo ha mostrado Clemens Schwaiger ${ }^{21}$ - Kant considera los preceptos de la prudencia como preceptos categóricos e incondicionados: el carácter hipotético y condicionado de estos mandatos constituye una adquisición de la reflexión kantiana, y no un dato originario.

Sin dudas, ha sido puesto en evidencia el aspecto principal de esta distinción, que consiste en una diferenciación neta y esencial entre las distintas formas de racionalidad práctica, de las cuales solamente los mandatos en sentido estricto pertenecen al ámbito de la moralidad. En general, queda por detrás la idea que las distintas formas normativas no pueden no estar coordinadas entre sí, aunque más no sea por la inevitable recurrencia a la razón instrumental, y por ende a los principios condicionados, también para el cumplimiento de los deberes morales. Es cierto, de todos modos, que se trata de una articulación que se produce bajo la hegemonía de los mandatos morales, que constituyen el cuadro normativo que impone realizar ciertas acciones y que, obviamente, limita el ámbito de la acción a lo que es moralmente lícito. En suma, la investigación sobre la esfera práctica toma caminos diferentes y si por un lado distingue los diversos tipos de normatividad y los diversos ámbitos a éstos correspondientes, por otro lado, se impone el problema de cómo estos ámbitos puedan coordinarse entre sí ${ }^{22}$. En una perspectiva de este tipo hay espacio también para los deberes indirectos - como ha puesto en evidencia recientemente Jens Timmermann - que se diferencian del deber eigentlich, pero constituyen sin embargo una parte, si bien secundaria, de la vida moral de los individuos y de sus procesos deliberativos ${ }^{23}$ : el tema de la deliberación es un tema al cual actualmente se le presta particular atención, sobre todo en virtud

20 Véase N. Hinske, Die Ratschläge der Klugheit im Ganzen der Grundlegung, en O. Höffe (hrsg.), Grundlegung zur Metaphysik der Sitten. Ein kooperativer Kommentar, Frankfurt a. M., Klostermann, 1989, pp. 131-147, p. 133.

21 C. Schwaiger, Kategorische und andere Imperative. Zur Entwicklung von Kants praktischer Philosophie bis 1785, Stuttgart-Bad Cannstatt, Frommann-Holzboog, 1999, p. 184.

22 Dos reflexiones kantianas pueden resultar útiles como ejemplo de lo que sostenemos, si bien requieren un comentario más amplio: «Der Wirkliche Zweck ist: Glücklich zu sein. Bedingungen sind Sittlichkeit und Geschicklichkeit (Refl. 6889, Ak. XIX 194); «Der allgemeine Zwek des Menschen ist Glükseeligkeit; was sie praktisch dazu Vorbereitet, ist Geschiklichkeit, was die Geschiklichkeit dirigirt, ist Klugheit; was endlich die Klugheit restringirt und dirigirt, ist Sittlichkeit» (Refl. 7058, Ak. XIX, 237). Véase C. Schwaiger, op. cit., pp. 184-185.

${ }^{23}$ Cfr. J. Timmermann, Kant su coscienza, dovere «indiretto» ed errore morale, en Etica e mondo in Kant (comp. Luca Fonnesu), Bologna, Il Mulino, 2008, pp. 165-188. 
del hecho de que la aplicación del imperativo categórico no puede ser algo mecánico ${ }^{24}$. La moralidad no puede dejar de tener en cuenta el bienestar, pues es el bienestar el que provee los medios para el cumplimiento del deber (y Kant menciona la habilidad, la salud y la prosperidad; Ak., V, 93; 100), mientras que el malestar podría facilitar las tentaciones para transgredir el propio deber; es por ello que la conquista de la felicidad puede - no debeconstituir un deber indirecto. Y se trata siempre de una autolegislación, o si el uso de este término puede resultar arduo, de una autorregulación, de la voluntad racional, como razón empírica práctica ${ }^{25}$. Más allá de esto, respecto de los consejos, no es difícil ver que en Kant el consejo tiende a presentar una dimensión intrasubjetiva, más que intersubjetiva (como en Hobbes o en Thomasius). El carácter indeterminado del concepto de felicidad deja al descubierto su dificultad para constituirse como proyecto coherente y a partir de aquí se puede entender por qué, para Kant, los consejos a los otros respecto de cómo pueden perseguir su propia felicidad son inverosímiles y, como mucho, negativos: «todo intento de decir positivamente a otro hombre - escribe Norbert Hinske - cómo puede o incluso cómo debe alcanzar la felicidad, se mueve constantemente en los límites de la presunción» ${ }^{26}$. Y esto es completamente coherente con el antipaternalismo kantiano que se extiende desde la ética a la política, y viceversa. En la esfera política el Estado no debe ocuparse de la felicidad de los ciudadanos, sino de sus derechos, y desde el punto de vista ético, la promoción de la felicidad ajena consiste en promover lo que los demás consideren como los fines más adecuados para alcanzar su felicidad, y no lo que a nosotros nos parezca tal (Ak., VI, 388; 240).

El límite, y peor aún, el error de toda la tradición ética consiste en haber puesto su atención solamente en los consejos - de la prudencia con vistas a la felicidad - confundiéndolos con los mandatos: todas las éticas materiales rechazadas por Kant en las distintas taxonomías de las teoría éticas, primero en la Fundamentación y más tarde en la Crítica de la razón práctica, cometen este error fundamental — agravado por el carácter indeterminado de la felicidad-, y por este motivo tales éticas logran justificar, o legitimar, sólo los consejos, mas no están en condiciones de justificar los mandatos morales. Kant, en cambio, ha logrado dar la fórmula, que era en realidad lo que hacía

24 Para un desarrollo de la teoría kantiana de la deliberación véase C. La Rocca, L'etica verso il mondo. Kant e il problema della deliberazione morale, en Etica e mondo in Kant, cit., pp. 123-143.

${ }^{25}$ La expresión tiene su origen en el clásico comentario de Lewis White Beck a la segunda Critica ((A commentary on Kant's Critique of practical reason, Chicago \& London, The University of Chicago Press, 1960, capítulos VI y VII); sobre este punto me permito remitir a mi texto Ragione pratica e ragione empirica pratica nel pensiero di Kant, en «Annali del Dipartimento di Filosofia dell'Università di Firenze», 1988, pp. 67-86.

${ }^{26}$ N. Hinske, Staatszwecke und Freiheitsrechte. Kants Plädoyer für den Rechtsstaat, en G. Birtsch (hrsg.), Grund- und Freiheitsrechte von der ständischen zur spätbürgerlichen Gesellschaft, Göttingen, 1987, pp. 375-391, p. 387. 
falta, ya que sería impensable que alguien — presuntuosamente — pretendiese «introducir siquiera un nuevo principio de toda la moralidad, como si dijéramos para inventarla por vez primera [...] Como si antes de él, el mundo hubiese ignorado lo que es el deber, o hubiese estado en un error total acerca de él» (Ak., V, 8 n.; 12). Y el descubrimiento de la fórmula correcta permite, en primer lugar, una correcta explicación de la moralidad, y en segundo lugar, integrar todas las formas de la racionalidad práctica dentro de esta última, o al menos dentro de su horizonte.

Con respecto a la articulación normativa de la moralidad, para Kant ésta se mueve completamente dentro de la esfera del mandato: el mandato es el principio unificador de la subjetividad moral y de su comportamiento, interno y externo. Pero esto no significa que en el interior mismo del mandato no se produzca una nueva articulación, que no se limita a la - por cierto, fundamental- distinción entre ética y derecho.

Kant expondrá la articulación normativa de la esfera específica del mandato sólo en la Metafísica de las costumbres, en la que presenta su propia doctrina officiorum, fruto de las innumerables dudas y de las dificultades que el filósofo debe resolver antes de poder dar, treinta años después del anuncio del proyecto, el sistema de la moral ${ }^{27}$.

Lo que sostiene la distinción entre las dos partes de la Metafísica de las costumbres - derecho y ética- es, una vez más, la distinción entre una esfera externa y una esfera interna, y no en el sentido de que la ética pensada por Kant sea una ética de la interioridad (como podría ser la ética thomasiana, si no interviniese el decorum), sino más bien en el sentido de que mientras la legislación jurídica custodia sólo el comportamiento externo, la legislación ética se dirige además a la esfera interna: todos los deberes son deberes éticos, pues la legislación ética exige, con respecto a los deberes jurídicos, la correcta motivación, la buena Gesinnung (Ak., VI, 219-20; 24-25). Sin embargo, los deberes éticos incluyen a otra clase de deberes, peculiarmente y exclusivamente éticos, que constituyen el objeto específico de la segunda parte de la Metafísica de las costumbres, los deberes de virtud.

Con la distinción entre deberes perfectos y deberes imperfectos Kant sigue de alguna manera la tradición, de la cual retoma el criterio del carácter coercitivo de las acciones externas (las que quedan sometidas también a la legislación jurídica). Pero la articulación normativa de los deberes no se limita a la distinción entre deberes (también) jurídicos — todos ellos deberes perfectos-y deberes de virtud: también dentro de los deberes de virtud Kant introduce una serie de distinciones, que indican que aun los deberes específica-

27 Con respecto a la génesis de la idea de una «metafísica de las costumbres», en Kant véase C. Cesa, Una metafisica della morale?, en Kant e la morale. A duecento anni da «La Metafisica dei costumi», Pisa-Roma, Istituti Editoriali e Poligrafici Internazionali, 1999, pp. 17-40; puede verse también S. Bacin, Sulla genesi della Metafisica dei costumi di Kant, en «Studi settecenteschi», 25-26, 2005-2006, pp. 253-279. 
mente éticos presentan caracteres constrictivos diferentes (y de mérito inverso). De este modo queda delineada una escala jerárquica de deberes, que es la siguiente: deberes jurídicos, deberes de virtud perfectos, deberes de virtud imperfectos de obligación estricta y deberes de virtud de obligación amplia ${ }^{28}$.

Conforme al mandato de la ley moral, Kant presenta una articulación del deber que cubre todo el ámbito normativo, y junto al criterio de la coerción, como criterio distintivo del derecho, coloca el criterio del carácter determinado del deber, es decir el criterio que remite a la cuestión de si y en qué medida el mandato del deber pueda determinar los modos, los tiempos y las formas de su cumplimiento.

El carácter indeterminado de los deberes imperfectos en su conjunto - lo cual no constituye una novedad kantiana- es fruto del carácter coercitivo - es decir del carácter negativo- de la legislación jurídica ${ }^{29}$, y de la especificad del objeto de la legislación ética en lo que hace a los deberes de virtud. La articulación normativa abarca todo el ámbito práctico bajo la categoría del mandato, y la distinción entre derecho y ética se basa en la distinción entre una legislación que custodia las acciones y una legislación que establece las máximas de las acciones, y esto da lugar a una articulación de los deberes que, en el caso de los deberes perfectos (jurídicos, los deberes de carácter más constrictivos, que permiten la convivencia pacífica y que están sujetos a una legislación externa, coactiva) tiene carácter negativo y se basa en las prohibiciones, mientras que en el caso de los deberes de virtud, se funda en determinadas máximas, las cuales también tienen carácter coactivo diferente, o una urgencia o accesibilidad diferente, pero que dejan un margen de indeterminación, una latitudo, con respecto a los modos de obrar con vistas al cumplimiento del deber. Lo que la legislación - también - interna, incoercible, de la ética manda es la adopción de una cierta máxima de la voluntad correspondiente a dos tipos de fines - la propia perfección y la felicidad ajena - de los cuales, sin embargo, sólo su persecución y no sus formas concretas, puede ser determinada a priori, y debe ser determinada por la reflexión y por la deliberación del sujeto en cada circunstancia. De este modo se crea una escala jerárquica de deberes que va de los más urgentes a los menos urgentes, de los más estrictos a los más amplios, con un valor inverso, pues los deberes más amplios son los deberes de mayor valor moral, que Kant llama meritorios (los deberes de amor).

En la Grundlegung y en la segunda Crítica Kant había mencionado de distintas maneras la doctrina de los deberes, sugiriendo ya distinciones entre formas diferentes del deber. Había hablado de deberes perfectos e imperfec-

28 Véase M. Baron, Kantian Ethics almost without Apology, Ithaca and London, Cornell University Press, 1999, pp. 31-32.

29 W. Kersting, art.cit.. 
tos, contingentes y obligatorios, necesarios y contingentes, estrictos y amplios. No es necesario detenerse sobre este punto, pero sí puede resultar útil observar que en la Doctrina del método de la Crítica de la razón práctica Kant - además de la firme polémica contra las acciones überverdienstlich, «nobles, sobremeritorias» (Ak, V, 155, 157; 162)— hace una observación que anticipa la perspectiva de la Metafísica de las costumbres, hablando precisamente de los deberes accidentales y esenciales, que se fundan respectivamente sobre «lo que de mí exige la necesidad (Bedürfnis) de los hombres a diferencia de lo que requiera de mí su derecho» (Ak., V, 159; 167). El fundamento de la distinción reposa en una atención distinta a la norma moral: «la atención a aquella ley que sólo ofrece un principio de obligación se distingue de aquella que es realmente obligatoria (leges obligandi a legibus obligantibus)» (Ak. V, 159; 167). Creo que aquí encontramos la raíz de la distinción de la Metafísica de las costumbres, como así también de algunos otros problemas.

Es interesante, si bien va más allá de los límites del presente ensayo, que Kant haya encontrado algunas dificultades o elementos que le generaran perplejidad durante su construcción, pues esto demuestra, una vez más, que su pensamiento no es algo preconstituido y que la obra de 1797 no es una obra de menor importancia. Se trata de problemas que muestran con claridad que el filósofo era conciente de la dificultad implícita en el intento de colocar en el centro de su construcción ética el concepto de fin, y más precisamente de un fin que es a la vez un deber (justamente la propia perfección y la felicidad ajena). De hecho, todos conocemos la polémica contra el concepto de fin de la voluntad como un objeto material de la voluntad, que caracteriza la Grundlegung y el proceder sistemático de los primeros capítulos de la Crítica de la razón práctica.

En el laboratorio de las Vorbereiten a la Doctrina de la virtud, es decir en el umbral de la redacción de la obra, Kant no está seguro de dar a los deberes de virtud el estatuto de los deberes fundados sobre leyes efectivas, pues estos deberes caen bajo «un principio de una legislación pero no pueden ser determinados por estas mismas leyes, es decir tienen una latitudem», y por este motivo las normas correspondientes podrían ser llamadas «Anmahnungen, recomendaciones, admonitiones» (Ak. XXIII, 380) y no leyes. Evidentemente, Kant no usa el término consejos, Ratschläge, que ya tiene otro significado. El principio normativo que se dirija a las máximas y no a las acciones, no puede ser llamado ley, efectivo mandato, sino admonitio; Kant lo retoma algunas páginas después hablando de un «principio de la máxima, no una ley de acciones determinadas» (Ak. XXIII, 393). En suma, en esta complicada reflexión kantiana pareciera percibirse el eco del viejo binomio consilium/praeceptum, a partir del cual lo que va más allá del deber más constrictivo, es decir jurídico, no puede ser objeto de ley sino solamente de admonitio, de un llamado a la acción que no tiene la fuerza vinculante de la ley, si bien 
Kant añada que se trata de objetos específicos del arbitrio que pertenecen a la ética y que son moralisch-nothwendig.

El hecho es que Kant habrá de optar por la solución que ve también en el deber de virtud el fruto de una ley, lo cual se queda claro ya en el título del § VI de la introducción a la doctrina e la virtud (Die Ethik giebt nicht Gesetze für die Handlungen (denn das thut das Ius) sondern nur für die Maximen der Handlungen). Con un poco de malignidad se podría percibir la conciencia kantiana de los problemas que ha debido afrontar, ya sea cuando niega con fuerza que por deber amplio se pueda entender «un permiso para introducir excepciones a la máxima de las acciones» (Ak., VI, 390; 242) —es una palinodia porque se trata de una hipótesis que él mismo había presentado via la definición de deber perfecto en la Fundamentación (Ak. IV, 421n: «entiendo aquí por deber perfecto aquel que excluye toda excepción a favor de la inclinación»); ya sea cuando parece explicar los motivos por los cuales ha optado por someter los deberes amplios a la ley: «[...] las máximas de las acciones pueden ser arbitrarias y están sometidas sólo a la condición restrictiva de ser idóneas para constituir una legislación universal, como principio formal de las acciones. Pero una ley elimina lo arbitrario de las acciones y se diferencia en esto de toda recomendación (Anpreisung) (en la que únicamente se requiere conocer los medios más adecuados para un fin)» (Ak. VI, 389; 242). Sin duda hay aquí muchos problemas, pero es necesario señalar que después de esta toma de posición definitiva desaparece una cierta terminología: no se habla más, como en la Fundamentación o en la segunda Crítica, de deberes accidentales o contingentes: el deber siempre es necesario, por definición, y esto es así, dice Kant sin dejar espacio a dudas, porque es el fruto de una ley, no de admonitiones o recomendaciones.

La articulación de los mandatos que expresan la ley moral genera una doctrina de deberes desarrollada de la manera ya mencionada. El espacio del deber abarca entonces todos los tipos de acciones moralmente significativas sin que haya ningún tipo de límite al deber, y por ende clases de acciones moralmente significativas situadas más allá de la obediencia al mandato. Esto demuestra que si la moral no es una moral de la prohibición, hecha solamente de deberes negativos, como se ha afirmado más de una vez (la mayor parte de los deberes de virtud son deberes positivos, y positivas son las clases generales a las que éstos pertenecen: la propia perfección y la felicidad ajena), ella tampoco es una moral mínima o, como piensan otros, una moral demasiado exigente: es cierto que el deber abraza toda la vida moral, pero la concepción de los deberes de virtud - positivos - como deberes amplios o imperfectos hace que el modo, el cómo y el grado de aplicación de estos deberes pertenezca al ejercicio de deliberación del individuo, justamente porque es el individuo el que decide y delibera concretamente sobre las formas para cumplir con las leyes dedicadas a las máximas.

La omnipresencia del mandato no implica que la moralidad sea invasiva y que se extienda sobre toda nuestra vida, como Kant declara explícitamente 
hablando del Phantastisch-tugendhaft, que podríamos traducir como «virtuoso fanático», es decir «aquel que no admite que haya cosas indiferentes (adiaphora) desde el punto de vista moral, que siembra todos sus pasos de deberes, como de cepos, y que no considera indiferente que me alimente de carne o de pescado, de cerveza o de vino, cuando ambos me son de provecho; hay aquí una micrología, cuyo dominio se convertiría en tiranía si la incluyéramos en la doctrina de la virtud» (Ak. VI, 409; 267).

Es cierto que Kant considera indispensable una perspectiva que no se limite a los deberes jurídicos. El filósofo examina explícitamente la hipótesis de una vida moral hecha solamente de deberes jurídicos, aunque cumplidos en modo ético, o sea con una buena Gesinnung, pero la rechaza porque tal perspectiva no permitiría determinar las ventajas que de ella podrían derivar para la felicidad de los hombres y para su misma imagen: «¿No sería mejor para el bien [Wohl] del mundo en general limitar toda la moralidad de los hombres únicamente a los deberes jurídicos, sin duda con la máxima escrupulosidad, pero situar la benevolencia entre las cosas indiferentes? No es tan fácil percatarse de las consecuencias que esto podría tener en la felicidad de los hombres. Pero en este caso faltaría al menos un gran adorno moral del mundo, la filantropía, que es necesaria por sí misma, aun sin tener en cuenta sus ventajas (para la felicidad), para representarse el mundo en su completa perfección como un hermoso todo moral» (Ak., VI, 458; 329).

Es entonces el derecho el que establece el cuadro normativo sobre el que se funda la vida social, y la dimensión de la socialidad adquiere un peso cada vez mayor en el pensamiento kantiano, paralelamente a una atención creciente de parte del filósofo respecto de la relaciones humanas y de la posibilidad de una progresiva Moralisierung, es decir de una realización de la moralidad ${ }^{30}$. El Kant de los años noventa presta mucha más atención a la hipótesis de una realización mundana de la moralidad que a los rasgos teológicos-morales que lo habían llevado, por ejemplo, a la formulación de los postulados de la segunda Crítica (no es casual, de hecho, que tal doctrina desaparezca del horizonte y no desempeñe ningún rol sistemático). La Metafísica de las costumbres cae dentro de este proyecto: se trata de una moral, de una doctrina de los deberes ética y jurídica, para los hombres, como queda claro ya a partir del concepto mismo de derecho; $y$, se podría añadir, se trata de una doctrina de los deberes (solamente para los seres racionales finitos la ley moral adquiere la forma de un mandato, ético o jurídico). En estos años parece disminuir progresivamente, por un lado, el providencialismo kantiano muy presente en el decenio anterior, y por otro, la constante insistencia sobre la interioridad, sobre el tema de la Gesinnung, que en la Metafísica de las cos-

30 He intentado argumentar esta tesis en un texto al cual me permito remitir: Kants praktische Philosophie und die Verwirklichung der Moral, in H. Nagl-Docekal - R. Langthaler (hrsg.), Recht - Geschichte - Religion. Die Bedeutung Kants für die Gegenwart, Berlin, Akademie Verlag, 2004, pp. 49-61. 
tumbres constituye una suerte de telón de fondo: esto no significa que Kant reniegue de lo que ha afirmado en sus textos anteriores; al contrario, pero aquí hay otros elementos que adquieren protagonismo, aunque la cuestión de la relación entre interioridad y exterioridad quede abierta y sin solución definitiva.

Las formas no jurídicas de las relaciones sociales están bien presentes en los distintos ciclos de clases de antropología, y aquí encontramos numerosas consideraciones sobre los «conceptos fundamentales de la praxis» (reglas, consejos, mandatos, pero sobre todo sobre los respectivos ámbitos normativos: habilidad, prudencia y moralidad). Recientemente Clemens Schwaiger ${ }^{31}$ ha dedicado mucha atención al estudio de estas clases, desde hace poco disponibles en la edición de la Academia.

La Klugheit-prudentia no es solamente el ámbito privado, individual, de la conquista de la felicidad personal - tarea demasiado ardua, como ya se ha dicho - sino que tiene que ver también, en otra acepción paralela y no separada de la primera, con la Weltklugheit, prudencia mundana, capacidad de interactuar con el prójimo, de tener un influjo sobre los otros hombres y de incluirlos en el propio proyecto de felicidad. Encontramos un indicio de esta idea, si bien breve, casi inasible y secundario si no tuviéramos presentes las clases de antropología, también en la Fundamentación, en una nota introducida por Kant durante la discusión sobre los imperativos: «La palabra sagacidad [Klugheit, prudencia] se toma en dos sentidos: en un caso puede llevar el nombre de sagacidad mundana; en el otro, el de sagacidad privada. La primera es la habilidad de un hombre que tiene influjo sobre los demás para usarlos en pro de sus propósitos; la segunda es el conocimiento que reúne todos esos propósitos para el propio provecho duradero. La segunda es propiamente la que da valor a la primera, y de quien es sagaz en la primera acepción, y no en la segunda, podría mejor decirse: es hábil y astuto, pero en total no es sagaz» (Ak. IV, 416 n.). La búsqueda de la felicidad, cuando se realice en forma racional y dentro de los límites de la moralidad, es una tarea no sólo individual sino además social. En el Umgang mit den Menschen ${ }^{32}$ está también el tema de la socialidad externa que abraza muchos otros aspectos, incluso los de la cortesía, los de la conversación o los de las buenas maneras; aspectos que Kant, como ya Thomasius, ve bien representados por Francia ${ }^{33}$. Este aspecto está bien presente en las clases de antropología, pero en la Metafísica de las costumbres será absorbido por el ámbito ético (mientras que la cortesía en la Grundlegung era considerada exclusivamente como consejo empírico de la prudencia: v. Ak., IV, 418).

31 C. Schwaiger, op. cit.

32 Así se llamaba el libro de Knigge publicado en 1788: Ueber den Umgang mit den Menschen.

33 Sobre esta cuestión puede resultar muy útil el libro de N. Pirillo, L'uomo di monto tra morale e ceto, cit. 
Al final de la Metafísica de las costumbres, en el apéndice, aparece el término ciceroniano y después thomasiano del decorum, que Kant incluye entre los deberes de virtud, es decir de las virtudes sociables, que remiten justamente al Umgang mit den Menschen (Umgangstugenden, las llama Kant). El término decorum no es muy utilizado por Kant, y en general remite al ámbito del comportamiento externo, si se quiere, al ámbito de las buenas maneras: también esta esfera cae bajo los deberes de virtud, en virtud de ese esfuerzo por valorizar la socialidad y la cultura, y por relacionar las esferas interna y externa, que caracteriza el pensamiento del filósofo. Y vamos a encontrar el mismo tono también en la antropología, aunque la versión publicada en 1798 no dedique mucha atención a aquella tríada normativa que tanto espacio ocupaba en las clases. Hay que desarrollar la propia weltbürgerliche Gesinnung. Es un deber de virtud - escribe Kant en la Metafisica de las costumbresdesarrollar las propias perfecciones éticas —officium commercii, sociabilitas- y no aislarse del mundo, «convertirse sin duda en el centro inmóvil de sus propios principios, pero considerar este círculo, trazado alrededor de sí, como parte de uno omniabarcante de carácter cosmopolita; no precisamente para fomentar lo mejor del mundo como fin, sino sólo para cultivar la comunicación recíproca, los medios que indirectamente conducen a ello, la amenidad en sociedad, el espíritu de conciliación, el amor y respeto mutuos (la afabilidad en el trato y el decoro, humanitas aesthetica et decorum), agregando de este modo la gentileza a la virtud; cosa que es incluso un deber de virtud. Ciertamente, se trata sólo de productos externos o de adornos (parerga), que prestan una hermosa apariencia de virtud, que tampoco engaña porque todos saben cómo interpretarla. Sin duda es sólo calderilla, pero favorece el sentimiento mismo de la virtud al esforzarse por aproximar en lo posible esta apariencia a la verdad, en la afabilidad, en el carácter expansivo, en la cortesía, en la hospitalidad, en la benignidad (en el rebatir sin disputar), que en su conjunto, como simples modales del trato, al manifestar obligaciones externamente obligan también a otros y que, por tanto, influyen a favor de la intención virtuosa al hacerla estimable al menos» (Ak. VI, 473-4; 350-351).

El problema de la exterioridad intersubjetiva, que incluye ante todo al derecho, pero también al aspecto «legal» (en el sentido kantiano) de los deberes de virtud, incluidas la cortesía y las «buenas maneras», tiene muchas dimensiones: por un lado se trata de comportamientos solamente externos, pero por otro tales comportamientos pueden tener un influjo positivo, como condiciones de algo más profundo y significativo.

No quisiera exagerar la importancia de esta atención de Kant respecto de las relaciones externas fundadas sobre las buenas maneras, pero creo que no se puede dejar de lado el rol positivo de la esfera externa del comportamiento, incluso en las buenas costumbres; y el hombre de mundo, el Weltmann, que conoce el mundo y los hombres y es capaz de interactuar con ambos, es aquel que está en camino de convertirse en Weltbürger. En la Antropología desde el 
punto de vista pragmático, publicada un año después que la Metafísica de las costumbres (1798), se pierde, como ya hemos dicho, la constante remisión presente en las clases de antropología a los distintos ámbitos normativos de la habilidad, de la prudencia y de la moralidad, pero se acentúa el rol positivo de las buenas costumbres, de la correcta socialidad, incluso en las buenas maneras; encontramos además muchas digresiones sobre las formas oportunas de la conversación. El hecho de que se trate de apariencia es de alguna manera algo negativo pero, Kant lo subraya, no se puede hablar de engaño porque todos saben que se trata de aspectos exquisitamente externos.

Si bien en el libro sobre la antropología del 1798 Kant no reserve ningún espacio a la tripartición de los ámbitos normativos de la habilidad, la prudencia y la moralidad, ésta se presenta aquí en la forma de un boceto de filosofía de la historia, que reproduce los caracteres de la tripartición en las diferentes disposiciones (Anlage) de la especie humana: técnica, pragmática —es decir de la Zivilisierung - , y moral (Ak., VII, 322 sgg.). Zivilisierung e Moralisierung no coinciden, pero Kant deja entrever que el progreso externo de la moralidad - que pasa a través de la promoción de una sociedad jurídicamente justa, pacífica, que tienda a una extensión y a una profundización cada vez mayor de sus propios deberes, incluso en las relaciones más cotidianaspuede crear las condiciones para un perfeccionamiento no sólo externo. La confianza en el progreso - que para el último Kant es un deber, y no el fruto de la providencia - se funda y se puede fundar solamente sobre nuestro compromiso para crear las condiciones externas necesarias a tal progreso: esto podrá tener algún influjo también sobre la moralidad de los hombres, entre otras cosas porque - rasgo utilitarista que no está ausente en Kant- una convivencia que tienda al respeto y a la benevolencia recíproca podrá facilitar la maduración de una Gesinnung adecuada, ya que desaparecerán las condiciones del conflicto y de la desconfianza intersubjetivos. En este sentido, el progreso del individuo corre paralelo al progreso de la especie: el deber del perfeccionamiento individual que se extiende en una articulación de deberes, desde los más estrictos a los más amplios, que marca la tarea de progreso moral, corresponde al progreso de la especie humana, ambos en el horizonte del mejoramiento moral.

\section{Como una apostilla: después de Kant}

Kant representa el momento más alto de la doctrina officiorum del siglo XVIII y al mismo tiempo constituye su punto culminante: en general, en la historia de la doctrina officiorum, con Kant se concluye la tradición que comienza con Grocio, Hobbes y Pufendorf, y que caracteriza la filosofía práctica moderna. La teoría de los deberes elaborada en el siglo XVIII, y aun la teoría kantiana, propone una concepción del deber omnicomprensiva, que carece de 
una limitación del deber: es dentro del espacio del mandato moral que en Kant se articula la distinción entre ética y derecho, como así también una progresión del deber que, en sus diferentes formas, exprime toda la trayectoria de la vida moral. El praeceptum ordena dentro de sí todas las formas normativas de la esfera práctica, asimilando en sí mismo el antiguo binomio mandato/consejo en una progresión articulada de los deberes. No existe nada, desde el punto de vista normativo, más allá del praeceptum.

Después de Kant, con Fichte y con Hegel, la reflexión sobre el deber adquiere una fisonomía diferente: surge la idea de una incorporación de los deberes del individuo en el tejido objetivo que constituye, para el individuo, una segunda naturaleza - la sociedad y la historia - y el punto de vista moral es incorporado dentro de una perspectiva que lo supera y lo integra, en la religión (Fichte), o en el tejido institucional de la eticidad (Hegel).

Durante el siglo XIX, la doctrina de los deberes que había dominado el debate ético durante dos siglos acusa una sustancial desaparición; se piense, por ejemplo, en los filósofos más importantes, y también en los representantes del movimiento neokantiano. La reflexión sobre las normas, como mandatos, tiende a desplazarse hacia el ámbito jurídico, y la figura del consejo desaparece de la filosofía práctica, con pocas excepciones (Mill, o Brentano, que recuperan elementos de la tradición).

El tema de los deberes volverá a aparecer en el siglo XX, por ejemplo en un filósofo que es también, y no por casualidad, un comentador de Kant, William David Ross, quien en los años Treinta con su libro, The right and the good, dará un aporte decisivo para una teoría deontológica - la más importante después de Kant - que tiene muchos elementos en común con la teoría kantiana (quizás más de los que el mismo Ross pensaba) ${ }^{34}$. En la obra de Ross encontramos el intento específico de promover una doctrina positiva de los deberes explícitamente sujetos a la latitudo kantiana: de hecho, el espacio para la reflexión y para los procesos deliberativos es amplio en la teoría rossiana de los deberes prima facie (que son principios, para Ross, en el sentido de los mandatos, y no de los consejos, pero es el sentido del mandato que aquí aparece debilitado).

La recuperación durante el siglo XX de la teoría de los officia ha despertado también muchas críticas, a partir de las reflexiones polémicas sobre la sensatez del concepto mismo de «deber» dentro de un horizonte secularizado (es decir privado no de la religión, sino de lo que Kant llamaba polémicamente la moral teológica); actitud polémica que constituye la base de las distintas formas de ética de la virtud y de la actitud crítica respecto de la teoría ética ${ }^{35}$.

34 Un nueva edición a cargo de P. Stratton-Lake ha sido publicada en el 2002 (Clarendon Press, Oxford).

35 Esta polemíca tiene su origen en el célebre ensayo de Elizabeth Anscombe sobre Modern moral philosophy, de 1958. 
Pero algunas de las reacciones críticas al deber nos conducen una vez más a nuestro tema. En 1958, el mismo año en que Elizabeth Anscombe lanza su ataque contra el deber en los términos antes señalados (retomando, creo sin darse cuenta, las tesis de Schopenhauer de 1841), J. O. Urmson ${ }^{36}$, probablemente siguiendo los pasos de Mill, introduce el problema de una delimitación del deber, tratando de distinguir los deberes en sentido estricto de las acciones que van más allá del deber, las llamadas acciones supererogatorias (término que habría de utilizar Chisholm poco tiempo después ${ }^{37}$ ).

El término es explícito y representa, es fácil decirlo, una suerte de venganza de Ambrosio y de Buenaventura: éste último había puesto su atención, siguiendo los pasos de Alessandro de Hales, sobre la supererogatio, para indicar las acciones que, en la escala de la perfección, cumplen no solamente con los preacepta sino también con los consilia ${ }^{38}$. El artículo de Urmson se ocupa de hecho de santos y de héroes, de sujetos capaces de realizar acciones más allá del deber, de acciones que desde esta perspectiva no pueden ser consideradas deber, pero que tampoco pueden ser consideradas como carentes de significado moral.

Urmson contrapone la supererogación a la moral mínima, ordinaria, del deber, reivindicando para la primera un espacio específico propio, y la noción de supererogación obtiene una suerte de colocación en un bello libro de David Heyd ${ }^{39}$ de 1981, en el cual la reivindicación del espacio de la supererogación se funda sobre la defensa de un espacio de libertad, de autonomía y de arbitrio del individuo; espacio que se coloca, una vez más, más allá del deber. Y dentro de este contexto asistimos a una recuperación —una vez perdido sin embargo el viejo galateo - de la importancia de la esfera de la cortesía, del decorum ciceroniano, como ámbito de acciones éticamente no indiferentes ${ }^{40}$.

Se trata de una nueva reformulación, la última, por ahora, de los problemas generados por el binomio mandato/consejo, que por supuesto ya no remite a la perfección y a la salvación, pero que sigue dando origen a formas

36 J.O. Urmson, Saints and heroes (1958), en J. Feinberg (ed.), Moral concepts, Oxford, Oxford University Press, 1969, pp. 60-73.

37 R. Chisholm, Supererogation and Offence, en «Ratio», 5, 1963, pp. 1-14.

38 Véanse los trabajos de Silvana Vecchio citados en la nota 1.

39 Supererogation. Its status in ethical theory, Cambridge, Cambridge University Press, 1982; véase también J. Janiaud, Au-delà du devoir. L'acte surérogatoire, Rennes, Presses Univ. de Rennes, 2007.

40 Con respecto a la relación entre ética y buenas maneras v. G.A. Johnston, Morals and Manners, in «International Journal of Ethics», 26, 1916, pp. 193-206; S. Buss, Appearing respectful: the moral significance of manners, en «Ethics», 109, 1999, pp. 795-826; N. Sherman, Of Manners and Morals, en «British Journal of Educational Studies», 53, 2005, pp. 272-289 y The Look and Feel of Virtue, en C. Gill (ed.), Virtue, Norms and Objectivitiy. Issues in Ancient and Modern Ethics, Oxford, Clarendon Press, 2005, pp. 59-92; K. Stohr, Manners, Morals and Practical Wisdom, en T. Chappell (ed.), Values and Virtues. Aristotelianism in Contemporary Ethics, Oxford, Oxford University Press, 2006, pp. 189-211. 
distintas de prescripción de la moralidad. No ha faltado entonces, quien - en estos años caracterizados por la recuperación del peso teórico de la ética kantiana - haya intentado hallar y sostener la existencia, en Kant, de un espacio de la supererogación.

Si en cambio Kant, como todo su siglo, no deja espacio a la supererogación ${ }^{41}$, y dirige una mirada crítica a santos y a héroes, como así también a la ética del entusiasmo y de las grandes acciones, depositando en cambio toda su expectativa en una articulación del deber en sus diferentes formas, esto no quiere decir de ninguna manera que el énfasis sobre la supererogación haya de llevarse la mejor parte: el instrumento kantiano del deber, si se lo considera en toda su complejidad, conserva toda su importancia y sigue siendo aun hoy una opción disponible. Kant hubiera estado de acuerdo con las palabras del Galileo brechtiano, para el cual es unglücklich das Land, das Helden nötig hat: infeliz el país que necesita héroes.

41 Como sostiene M. Baron: v. Kantian Ethics Almost Without Apology, cit., para la polémica respecto de M.J. Gregor y T. Hill, en particular toda la primera parte, pp. 88 y sig. 